Original article

\title{
Epidemiology of nosocomial infection in Abadan, Southwest Iran
}

\author{
Mohammad Javad Mohammadi $^{\mathrm{a}}$, Aliasghr Valipour ${ }^{\mathrm{b}}$, Gholamreza Sarizadeh ${ }^{\mathrm{a}}$, \\ Habib Allah Shahriyari ${ }^{\mathrm{c}}$, Sahar Geravandi ${ }^{\mathrm{d}}$, Mahboobeh Momtazan ${ }^{\mathrm{e}}$, Jamshid Bahmaei ${ }^{\mathrm{f}}$, \\ Noorollah Tahery ${ }^{\mathrm{e}}$, Arghavan Afra ${ }^{\mathrm{e}}$, Babak Rastegarimehr ${ }^{\mathrm{e}, * *}$

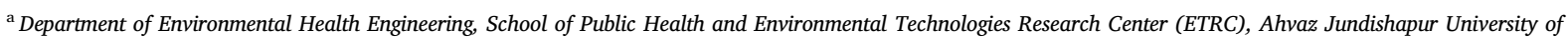 \\ Medical Sciences, Ahvaz, Iran \\ ${ }^{\mathrm{b}}$ Department of Health Management and Economics, School of Public Health, Tehran University of Medical Sciences, Tehran, Iran \\ ${ }^{\mathrm{c}}$ School of Public Health, Ahvaz Jundishapur University of Medical Sciences, Ahvaz, Iran \\ ${ }^{\mathrm{d}}$ Asadabad School of Medical Sciences, Asadabad, Iran \\ e Abadan Faculty of Medical Sciences, Abadan, Iran \\ ${ }^{\mathrm{f}}$ Student Research Committee, Management and Medical Informatics Faculty, Shiraz University of Medical Sciences, Shiraz, Iran
}

\section{A R T I C L E I N F O}

\section{Keywords:}

Frequency

Nosocomial

Infections

Abadan

\begin{abstract}
A B S T R A C T
Introduction: In medical centers one of the most important agents that can threated health patients and health care workers (HCWs) is Nosocomial infections (NIs).

Objective: The purpose of this study was to investigation of the relative frequency of NIs in Abadan, southwest of Iran.

Methods: In this descriptive study, the population under study contains on all the patients in Abadan teaching Hospitals, during 2015-2016. We in this study different information include ward of hospitalization, type of NI and patients' site of infection were collected. In this study, in order to analyze Excel, SPSS 16.0 and descriptive statistical methods were utilized.

Results: The results of the present study showed that the relative frequency of NIs was low $(<4 \%)$ found in this hospital during 2015-2016. According result our study, ICU and OBGYN was the most number of NIs. Result our stud showed that frequency of NIs was very lower in comparison with standard.

Conclusion: The most important the reasons for this low cases is as follows training programs related to the prevention of NIs.
\end{abstract}

\section{Introduction}

According to scientific findings, occur infection among patient's during 48-72 $\mathrm{h}$ after hospital admission is the definition of Nosocomial infections (NIs). ${ }^{1}$ NIs are among the most important causes of mortality, disability, prolonged hospitalization duration, high hospital costs, and high incidence of health problems in medical centers. ${ }^{2,3}$ Among the most important threats for health care workers (HCWs) are those NSIs. ${ }^{4-6}$ The most common infections are pneumonia, urinary tract infection (UTI), surgical site infections (SSIs), and bloodstream infection (BSI). ${ }^{7-13}$ Needle stick injuries (NSIs) are among the common injuries in the teaching hospitals and medical centers. NSIs commonly occur during needle recapping, drawing blood, transit disposal needle, passing the needles between personnel, needles penetration through the gloves and the skin, placing the needles in a poorly located sharps container, and failure to use appropriate personal protective equipment which are increasing among hospital admissions and resistance to a variety of antibiotics in the treatment of NIs. ${ }^{14-16}$ Within the HCWs in regard to the risk of NSIs, nurses, surgeons and anesthesiologists, residents, midwives, operating room technicians, nurse aid, and workers tend to show relatively high rates, and radiologists and pediatricians relatively low rates of NSIs. ${ }^{17-20}$ Strategies for the reduction of the risk of NIs and NSIs can include training of appropriate HCWs, increasing knowledge of authorities about these infections, avoiding hand-to-hand passing of sharp instruments, reduction of use of sharp devices, using useful safety boxes, and reduction of direct contact with needles and disposals. ${ }^{21}$ Several study showed that education is the most important action for decrease the rate of NIs and NSIs. ${ }^{22}$ The rate of infection in a study by Maa et al. was about $40 \% \cdot{ }^{23}$ Luzzati et al. in Triveneto area, Italy reported that the most important factor affecting the incidence of infection was hospitalization and the most common NIs were pulmonary infections in Intensive Care Units (ICU). ${ }^{24}$ In similar work

\footnotetext{
${ }^{*}$ Corresponding author. Abadan School of Medical Sciences, Abadan, Iran. Tel.: + 989355439707.

E-mail address: babakrm@gmail.com (B. Rastegarimehr).
} 
Amini et al. studied the Frequency of NIs in Mostafa Khomeini Hospital, Arak. Their reported that the rates of surgical site infections were high and was highest in the ICU ward. ${ }^{25}$ The National Nosocomial Infections Surveillance (NNIS) reported that the number of NIs were 8833 devicerelated infections in adults. ${ }^{26}$ Greatest concern among HCWs are performing invasive procedures because of the danger of transferring BBIs. $^{21,27}$

This study aimed to determine the epidemiology of nosocomial infection in Abadan, Southwest Iran, during 2015-2016.

\section{Materials and methods}

\subsection{Methods}

The cross-sectional study was performed among all the patients in Abadan teaching Hospitals, in the southwest of Iran during 2015 up to 2016.

This study was approved by the ethics committee of Abadan Faculty of Medical Sciences, Abadan, Iran (ethic no. IR.ABADANUMS.REC.1396. 248) in accordance with Helsinki declaration and guidelines. Criteria for the diagnosis of NIs were based on the National Nosocomial Infections Surveillance (NNIS). ${ }^{28,29}$ In the present study, hospital supervisors of the infection control reported cases of NIs and NSIs, wards in which occurred and the sampling methods. NIs sampling was performed at random from patients with infections. Data about the patients' site of infection, ward of hospitalization, and type of NIs were collected.

\subsection{Description of study area}

Abadan $\left(30^{\circ} 20^{\prime} \mathrm{N}, 48^{\circ} 17^{\prime} \mathrm{E}\right)$, with a population of more than 300,000 individuals, is one of the metropolitans in Khuzestan province. ${ }^{30}$ Location of Abadan in the southwest of Iran (Fig. 1).
Table 1

Distribution of occupational NSIs in the hospital wards during 2015-2016.

\begin{tabular}{lll}
\hline Hospital ward & Number of NIs 2015 & Number of NIs 2016 \\
\hline ICU & $51(33.11 \%)$ & $50(26.45 \%)$ \\
Internal wards & $33(21.42 \%)$ & $18(9.52 \%)$ \\
General surgery & $27(17.53 \%)$ & $35(18.51 \%)$ \\
OBGYN wards & $34(22.07 \%)$ & $52(27.51 \%)$ \\
CCU & $1(0.65 \%)$ & - \\
Emergency wards & $6(3.89 \%)$ & $25(13.22 \%)$ \\
Operating room & $2(1.29 \%)$ & $9(4.76 \%)$ \\
\hline
\end{tabular}

Abbreviations: OBGYN: Health care worker; ICU: Intensive care unit.

\subsection{Statistical Analysis}

The coded data were entered in SPSS software version 16. Data analyses were performed using descriptive statistics (frequency, mean, and standard deviation for each variable).

\section{Results}

The number of NIs and NSIs in different wards of the hospital, including ICU, OBGYN, Internal, general surgery, emergency, operating room, and CCU, during 2015-2016 are presented in Table 1.

The number of cases of NIs was154 and 189 in 2015 and 2016, respectively. Totally, relative frequency of NIs was $3.214 \%$ and $2.89 \%$ in 2015 and 2016, respectively, in Abadan teaching hospitals. SSIs were the most frequent category of infection $(54.55 \%)$, followed by blood stream infections (BSIs) (19.48\%), pneumonia (18.18\%) and UTI (7.8\%) during 2015-2016 (Fig. 2).

\section{Discussion}

In recent years, NIs have been considered a serious threat to the
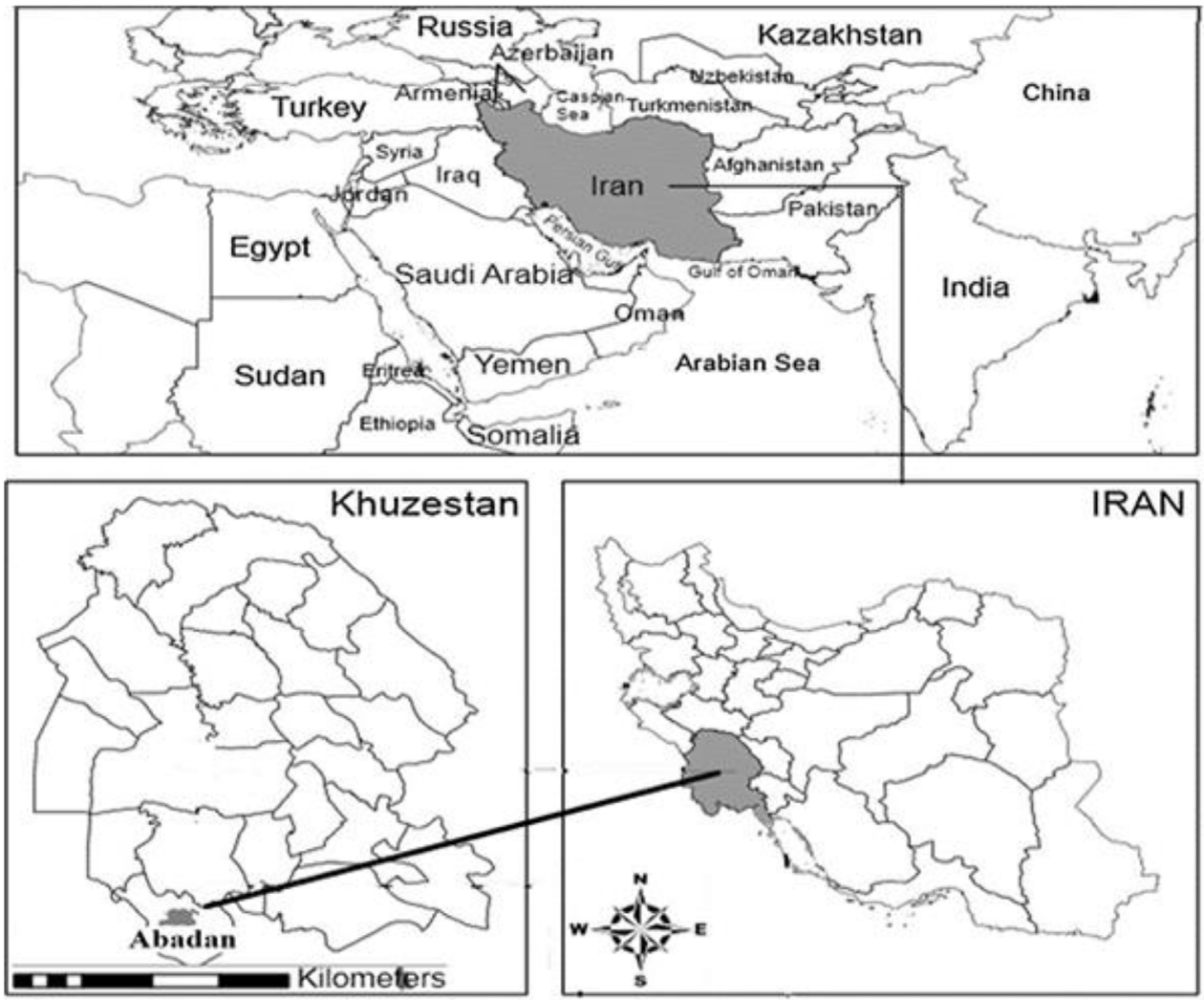

Fig. 1. Location of Abadan as the study area. 


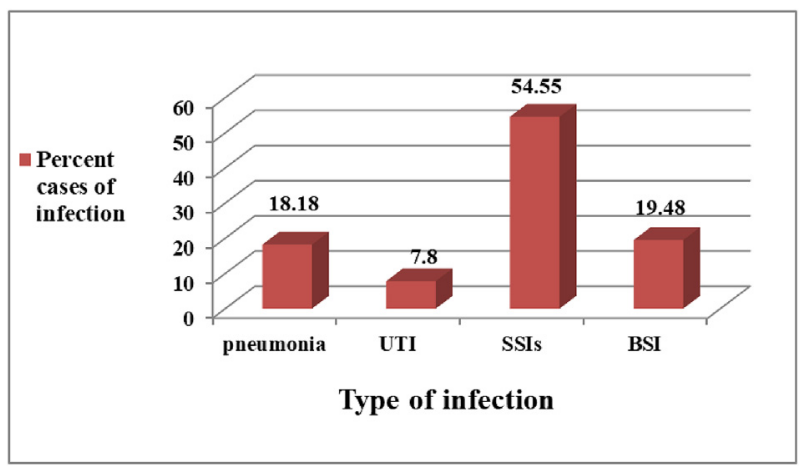

Fig. 2. Percentage of NIs based on type of infection, Abadan teaching Hospitals, during 2015-2016.

quality of life and health of patients. The undertaken study showed, case of high risk injuries related to needle sticks, contaminated sharp and cutting objects, respectively. Based on the results of this research, the number of cases of NIs was 154 and 189 during 2015 and 2016, respectively, and relative frequency was $3.214 \%$ and $2.89 \%$ in 2015 and 2016, which was lower compared to rates of referenced NIs in the guideline book. According to the results of our study, SSIs were the most common type of infection in our hospital. Qader et al. (36) and Luzzati et al. (24) reported in their studies that pneumonia was the most common type of infection. These differences may be due to the number of patients studied, place of study, and genetic susceptibility.

In several studies, Zolldann et al. (38), Unal et al. (39), Jeong et al. (40), and Kaoutar et al. (41), to summarize, showed that ICU ward had the highest rate of NI as compared to other wards.

\section{Conclusion}

The results of our study showed that an increase in the HCWs knowledge can reduce the rate of NIs. In conclusion, the relative frequency rate of NIs among patients, respectively, in this hospital was low. The reason in which cause the low frequency of nosocomial infection in a hospital in Abadan, Iran perhaps could be the result of refusing the cases NIs report, under diagnosis by HCWs of educational hospital. We believe that this information is useful not only for HCWs, but also for administrators and others involved in the care of patients and residents of long-term care facilities inasmuch as there are little published comparative data on yearly rates of NIs among patients. It should be mentioned that necessary to continuous supervision, careful monitoring of surveillance system, maintain continuous surveillance and health education are necessary to reduce NIs and their adverse effects.

\section{Limitations and strengths}

The major limitations of this study were shortcomings in Iranian health registry system, was the biggest problem in accurate estimation of rates of NIs in this study. In summary, we believe this information is useful not only for us but for others involved in the care of residents in long-term care facilities inasmuch as there are little published data on yearly NIs rates among patients.

\section{Funding/support}

The authors gratefully acknowledge Abadan Faculty of Medical Sciences, Abadan, Iran for financial support and providing necessary facilities to accomplish thus research with project number of 96U-24.

\section{Declaration of competing interest}

Authors have no conflict of interests.

\section{Acknowledgements}

The authors would like to thank Student Research Committee, Abadan Faculty of Medical Sciences, Abadan, Iran for providing financial supported by the grant: (96 U-24) of this research.

This study was supported by Abadan Faculty of Medical Sciences, Abadan, Iran for providing ethical issue: (IR.ABADANUMS.REC.1396. 248) of this research.

\section{References}

1. Salmanzadeh S, Yousefi F, Ahmadi F, et al. Evaluation of nosocomial infections in a teaching hospital. Avicenna J Clin Microbiol Infect. 2015;2:e29760.

2. Ahmadi F, Abolghasemi S, Parhizgari N, Moradpour F. Effect of silver nanoparticles on common bacteria in hospital surfaces. Jundishapur J Microbiol. 2013;6:209-214.

3. Nashibi R, Mohammadi MJ, Alavi SM, et al. Infection after open heart surgery in Golestan teaching hospital of Ahvaz, Iran. Data in brief. 2018;16:478-482.

4. Alavi SM, Sharifi M. Percutaneous injuries and transmission of HIV among cases referred for post exposure prophylaxis to razi hospital in ahvaz, a city in the southwest Iran. Jundishapur J Microbiol. 2013;6.

5. Laishram J, Keisam A, Phesao E, Tarao M, Laloo V, Devi H. Prevalence of needle stick injuries among nurses in a tertiary care hospital and their immediate response. Int $J$ Med Publ Health. 2013;3:257.

6. Dasgupta S, Das S, Chawan NS, Hazra A. Nosocomial infections in the intensive care unit: incidence, risk factors, outcome and associated pathogens in a public tertiary teaching hospital of Eastern India. Indian J Crit Care Med : Peer-Reviewed Offc Pub Indian Soc Crit Care Med. 2015;19:14-20

7. Javanbakht A, Askari E, Danesh L, Moghadas N, Mostafavi I, Naderinasab M. The incidence of cross infections in Imam Reza hospital, Mashhad, Iran. Iran J Microbiol 2012;4:177-179.

8. Saeidimehr S, Geravandi S, Rahim F, et al. Nosocomial infection rates during one year in naft grand hospital, ahvaz, Iran. Jundishapur J Health Sci. 2015;7:e30124.

9. Black SR, Weaver KN, Weinstein RA, et al. Regional infection control assessment of antibiotic resistance knowledge and practice. Infect Control Hosp Epidemiol. 2015;36:381-386.

10. Chaudhuri AK. Infection control in hospitals: has its quality-enhancing and cost-effective role been appreciated? J Hosp Infect. 1993;25:1-6.

11. Unti JA. Medical and surgical tourism: the new world of health care globalization and what it means for the practicing surgeon. Bull Am Coll Surg. 2009;94:18-25.

12. Siddique K, Mirza S, Tauqir SF, Anwar I, Malik AZ. Knowledge attitude and practices regarding needle stick injuries amongst healthcare providers. Pakistan J Surg. 2008;24:243-248

13. Rezai MS, Pourmousa R, Dadashzadeh R, Ahangarkani F. Multidrug resistance pattern of bacterial agents isolated from patient with chronic sinusitis. Caspian J Intern Med. 2016;7:114-119.

14. Mathei C, Niclaes L, Suetens $C$, Jans B, Buntinx F. Infections in residents of nursing homes. Infect Dis Clin. 2007;21:761-772 ix.

15. Ayas NT, Barger LK, Cade BE, et al. Extended work duration and the risk of selfreported percutaneous injuries in interns. JAMA. 2006;296:1055-1062

16. Geravandi S, Alavi SM, Yari AR, et al. Epidemiological aspects of needle stick injuries among health care workers in razi hospital ahvaz, Iran. 2015. Archives of Hygiene Sciences. vol. 5. 2016; 2016:85-91.

17. Wicker S, Jung J, Allwinn R, Gottschalk R, Rabenau HF. Prevalence and prevention of needlestick injuries among health care workers in a German university hospital. Int Arch Occup Environ Health. 2008;81:347-354.

18. Jayanth S, Kirupakaran H, Brahmadathan K, Gnanaraj L, Kang G. Needle stick injuries in a tertiary care hospital. Indian J Med Microbiol. 2009;27:44.

19. Memish ZA, Assiri AM, Eldalatony MM, Hathout HM, Alzoman H, Undaya M. Risk analysis of needle stick and sharp object injuries among health care workers in a tertiary care hospital (Saudi Arabia). J Epidemiol Global Health. 2013;3:123-129.

20. Cheraghi MA, Nejad EM, Begjani J, Rabirad N, Ehsani SR, Kaji MA. Knowledgeand attitudes of nurses regarding HIV/AIDS (Tehran-2010). Iran J Clin Infect Dis. 2011;6:121-123.

21. Makary MA, Al-Attar A, Holzmueller CG, et al. Needlestick injuries among surgeons in training. N Engl J Med. 2007;356:2693-2699.

22. Crivaro V, Bogdanovic L, Bagattini M, et al. Surveillance of healthcare-associated infections in a neonatal intensive care unit in Italy during 2006-2010. BMC Infect Dis. 2015;15:152.

23. Maa SH, Lee HL, Huang YC, et al. Incidence density and relative risk of nosocomial infection in Taiwan's Only Children's Hospital, 1999-2003. Infect Control Hosp Epidemiol. 2008;29:767-770.

24. Luzzati R, Antozzi L, Bellocco R, et al. [Prevalence of nosocomial infections in in tensive care units in Triveneto area, Italy]. Minerva Anestesiol. 2001;67:647-652.

25. Amini M, Sanjary L, Vasei M, Alavi S. Frequency evaluation of the nosocomial infections and related factors in Mostafa Khomeini hospital" ICU" based on" NNI" system. J Ardabil Univ Med Sci. 2009;7:9-14.

26. Reed D, Kemmerly SA. Infection control and prevention: a review of hospital- 
acquired infections and the economic implications. Ochsner J. 2009;9:27-31.

27. Control CfD. Bloodborne Infectious Diseases: HIV/AIDS, Hepatitis B, Hepatitis C: Emergency Needlestick Information. 2010; 2010.

28. System NNIS. National nosocomial infections surveillance (NNIS) system report, data summary from january 1992 through june 2004, issued october 2004. Am J Infect Contr. 2004;32:470.
29. Effatpanah M, Effatpanah H, Geravandi S, et al. he prevalence of nosocomial infection rates and needle sticks injuries at a teaching hospital, during 2013-2014. Clinical Epidemiology and Global Health. 2020; In press.

30. Mohammadi MJ, Rajaei Behbahani N, Geravandi S, Momtazan M, Mahboubi M, Alizadeh R. Association of mortality rate caused by traffic accidents in Abadan during 2012-2013. Arvand J Health Med Sci. 2017;2:23-28. 